\title{
Authentication of commercial candy ingredients using DNA PCR-cloning
} methodology

Marta Muñoz-Colmenero ${ }^{*}$, Jose Luis Martínez², Agustín Roca ${ }^{1}$, Eva García-Vázquez ${ }^{1}$

1- Laboratory of Genetics of natural resources, Area of Genetics, Department of Functional Biology, University of Oviedo, Asturias, Spain.

2- Sequencing Unit of the University of Oviedo, Asturias, Spain.

*- Corresponding author: Marta Muñoz Colmenero. Address: Faculty of Medicine, C/Julian Clavería s/n, Oviedo, 33006, Spain; Phone: +34 985102726; Fax: +34 985103534; e-mail: a.martam.colmenero@gmail.com 
1 Abstract

2 BACKGROUND: Commercial candies are consumed by all population age sectors

3 worldwide, thus methods for quality control and composition authentication are needed

4 for best compliance of consumer's preferences. In this study the applications of DNA-

5 based methodology for candy quality control have been tested. Eighteen samples of

6 commercial candies (marshmallows, gumdrops, jelly, sherbet, gelatin-based desserts)

7 produced by five countries were analyzed to identify the component species by

8 Polymerase chain reaction, cloning and sequencing of 16S rRNA and ribulose -1,5-

9 diphosphate carboxylase oxygenase genes, and the species determined from BLAST

10 comparison with universal databases and phylogenetic analysis.

11 RESULTS: Positive DNA extraction and amplification of the target genes was obtained

12 for $94 \%$ of candies assayed, even those containing as little as $<0.0005 \mathrm{ng} / \mu \mathrm{l} \mathrm{DNA}$

13 concentration. The results demonstrated that the species detected from DNA were

14 compatible with the information provided on candy labels only in a few products. DNA

15 traces of undeclared species, including fish, were found in most samples, and two

16 products were labeled as vegetarian but contained porcine DNA.

17 CONCLUSION: Based on the inaccuracy found on the labels of sweets we recommend

18 the use of DNA tests for quality control of these popular sweets. The DNA-tests have

19 been useful in this field but Next Generation Sequencing methods could be more

20 effective.

22 Keywords: Candy products, DNA tests, vegetarian labeling, consumer's choice,

23 traceability, labels. 


\section{INTRODUCTION}

26 Candies are consumed worldwide in different cultures and countries. ${ }^{1}$ The use of sweets

27 in human diet is very old: ancient Arabian, Chinese and Egyptian peoples consumed

28 candied fruits and nuts cooked with honey, and the Aztecs made a chocolate drink with

29 cocoa seeds. ${ }^{2}$ Now candies are consumed by all population sectors and ages; since they

30 are especially popular for children, ${ }^{3,4}$ their quality control should be a priority.

31 The composition of commercial candies and sweets is complex and often includes many

32 food additives and preservatives. ${ }^{5}$ Many products like soft and jelly-based candy

33 contain gelatin, which is frequently made from pig and cow. ${ }^{6,7}$ The presence of these

34 animals in candy may raise ethical or religious issues in some consumer sectors, for

35 example in vegetarians and in Halal-Kosher consumers, ${ }^{7}$ and consumers should be

36 informed about their choice. Information about the ingredients is important for

37 consumer's health also, since adverse reactions have been reported for allergic patients

38 who consumed candies without knowing they contained saffron, ${ }^{8,9}$ cochineal-made

39 carmine ${ }^{9}$ and peanuts. ${ }^{10}$ Anaphylactic shocks after eating marshmallows made from

40 undisclosed fish gelatin have been also documented. ${ }^{11}$ Therefore, disclosing full

41 information about the species contained in commercial candies is essential for

42 consumers to know what they are eating and help them to make ethical and safe choices.

43 Determining the species composition in commercial candies is not easy because they are

44 generally highly processed and can contain a mixture of products. DNA has been often

45 used for determining species composition in food, and nowadays the techniques for

46 DNA extraction and amplification by Polymerase chain reaction (PCR) allow the

47 successful analysis of highly processed products, ${ }^{12-15}$ detecting even small traces. ${ }^{16}$ In

48 the present study we have purchased different types of candies produced by five 
49 countries, for determining their species composition employing DNA-based molecular

50 techniques. Two different primer sets specific for animal or plant species were

51 employed for PCR amplification and cloning of DNA extracted from the candies. From

52 the results we have assessed the utility of this DNA-based methodology for quality

53 control in candy markets. The following parameters were considered for the assessment:

54 DNA content, PCR-amplification success, number of species detected, accuracy of

55 species identification (from concordance of two assignment methods, BLAST-based

56 and phylogenetic). In addition, comparing the detected and declared species we have

57 evaluated the accuracy of current candy labelling to recommend improvements in

58 quality control, if needed.

\section{EXPERIMENTAL}

60

\section{Sampling}

Eighteen candies from five countries: Spain ( 8 samples), France (2 samples), Portugal (4 samples), Sweden (1 sample), Spain/Portugal (2 samples), Spain/Turkey (1 sample) were analyzed (Table 1). Different products were considered (Fig. 1), including raw gelatin powder (3), desserts (3), soft candies (7), marshmallows (2), gums (2) and sherbet powder (1). The information provided in each candy label was analyzed in detail, especially the list of ingredients, allergy warnings and indications for specific consumer sectors such as vegetarians, vegans and persons with food restrictions.

\section{DNA extraction, quantification, PCR amplification and sequencing process}

DNA analysis was carried out in strict sterile conditions to prevent contamination, and both pre- and post-PCR processes were controlled. Sample manipulation was done within a sterile room cleaned with $100 \%$ ethanol and $10 \%$ bleach. All the material employed was cleaned and put in sterile bags to autoclaving. DNA extraction and PCR 
amplification were performed into a flow chamber within that sterilized room, with ultraviolet light to ensure destruction of any possible contaminant DNA. During all the process researchers wore two pairs of gloves, paper mask and cap and laboratory coat.

Negative controls were used to check possible contamination during the laboratory analysis, from the DNA extraction process to the visualization of PCR products in agarose gels. Pig (Sus scrofa) and rainbow trout (Oncorhynchus mykiss) were used as positive controls of animal detection with the 16S rRNA gene, and apple (Malus domestica) was the positive control for plant detection with rbcL gene. For the rest of post-PCR processes we worked in other laboratory within another flow chamber, also under ultraviolet light.

DNA extraction was performed with the kit DNeasy Mericon Food Kit of QIAGEN. From each candy four Eppendorf tubes with $200 \mathrm{mg}$ each one were employed for DNA extraction to get more amount of DNA. Two cleaning steps were done to eliminate potential inhibitors of polymerase chain reaction: first with CTAB detergent and second with chloroform. After, the contents from the four tubes of the same candy was put together to continue with the rest of the protocol. DNA was quantified using Qubit dsDNA HS Assay Kit in a Qubit 2.0 Fluorometer. The detection limit of this method is $0.0005 \mathrm{ng} / \mu 1$.

PCR amplification was done with the kit PCR core Kit Plus of Roche, with the enzyme uracil glycosylase and dideoxynucleotide with uracil instead of thymine. Since candies are highly processed their DNA is likely degraded, ${ }^{17}$ therefore we targeted short species-specific sequences. For animal species we employed the primers 16S-HF 5'ATAACACGAGAAGACCCT-3' and 16S-HR 5'-CCCRCGGTCGCCCCAAC-3' developed by Horreo et al. ${ }^{18}$ that amplify an $80-122$ base pair (bp) fragment within the 16S rRNA gene. PCR reaction was performed with: $5 \mu 1$ of DNA extraction from the 
candy (from less than $0.0005 \mathrm{ng} / \mu \mathrm{l}$ to $0.328 \mathrm{ng} / \mu \mathrm{l}$ ), $0.125 \mu \mathrm{l}$ of Taq polymerase from the

99 PCR core Kit Plus of Roche, polymerase solution with $\mathrm{Mg}^{2+} 1 \mathrm{x}, 0.5 \mu$ l of each primer

100

$10 \mu \mathrm{M}, 0.5 \mu 1$ dideoxynucleotides (dNTPs with $\mathrm{U}$ ), $0.5 \mu \mathrm{l}$ of Uracil glycosylase and bi-

101

distilled water up to $25 \mu \mathrm{l}$ of total volume. The PCR conditions were: a cycle at $20^{\circ} \mathrm{C}$

102

for $5 \mathrm{~min}$ and at $95^{\circ} \mathrm{C}$ for $2 \mathrm{~min}$ to activate and deactivate the uracil glycosylase enzyme

103

respectively; then, 40 cycles at $95^{\circ} \mathrm{C}$ for $30 \mathrm{~s}, 55^{\circ} \mathrm{C} 30 \mathrm{~s}, 72^{\circ} \mathrm{C} 1 \mathrm{~min} 30 \mathrm{~s}$, and a final cycle

104

at $72^{\circ} \mathrm{C}$ during $7 \mathrm{~min}$. For plant species we employed the primers Plant159-F

105

CTTGATTTTACCAAAGATGATGA and Plant159-R

106 TTCTTCGCATGTACCCGCAG designed by Han et al. ${ }^{19}$ for amplifying a $159 \mathrm{bp}$

107 fragment of the ribulose-1,5-diphosphate carboxylase oxygenase gene (rbcL). PCR

108 reaction was performed in the same way than $16 \mathrm{~S}$ rDNA gene but the PCR conditions

109 after the cycle for uracil glycosylase enzyme were 50 cycles at $95^{\circ} \mathrm{C}$ for $30 \mathrm{~s}, 58^{\circ} \mathrm{C} 30 \mathrm{~s}$,

$11072^{\circ} \mathrm{C} 1 \mathrm{~min} 30 \mathrm{~s}$, and a final cycle at $72^{\circ} \mathrm{C}$ during $7 \mathrm{~min}$.

111 PCR products were run in 2\% agarose gels stained with ethidium bromide. Purification

112 of PCR product was performed with IllustraIM ExostarIM 1-Step de GE Healthcare

113 Life Sciences. Direct sequencing was performed at the sequencing facilities of the

114 University of Oviedo employing BigDye Terminator Cycle Sequencing chemistry and

115 ABI Prism 3130xl Genetic Analyzer. Chromatograms evidenced species mixture, thus

116 cloning approaches were employed to obtain individual sequences. After purification of

117 PCR product with Wizard SV Gel and PCR Clean-Up System Kit (Promega), the

118 purified DNA was cloned using the Dual Promoter TA Cloning Kit (Invitrogen), with

119 pCR II vector and competent cells TOP10'. Briefly, we did the ligation and performed a

120 transformation process by thermal shock. Then the bacteria (Escherichia coli) were

121 grown in liquid SOC medium for 1 hour and spread on solid LB medium with

122 ampicillin. When bacteria grew (only bacteria carrying the vector are ampicillin- 
123 resistant) we picked white colonies, which carry the insert (their $\beta$-galactosidase gene is

124 interrupted) in $50 \mu$ l of bidistilled water. DNA was extracted from the colonies by

125 thermal shock at $95{ }^{\circ} \mathrm{C}$ during 5 min and a PCR was performed using the primers $\mathrm{T} 7$

126 and SP6 located in the flanking regions of the insertion site. The reaction mix of this

127 PCR was: 1.5 units of Taq polymerase of Biotools $(5 \mathrm{U} / \mu \mathrm{l})$, polymerase solution $1 \mathrm{x}, 1.5$

$128 \mathrm{mM}$ of $\mathrm{Mg} 2+, 1 \mu \mathrm{l}$ of each primer $10 \mu \mathrm{M}$, dideoxynucleotides (dNTPs) of $2.5 \mathrm{mM}$ and

129 bidistilled water up to $20 \mu \mathrm{l}$ of total volume. PCR conditions were: a cycle at $95^{\circ} \mathrm{C}$ for 5

$130 \mathrm{~min} ; 35$ cycles at $95^{\circ} \mathrm{C}$ for $30 \mathrm{~s}, 55^{\circ} \mathrm{C} 30 \mathrm{~s}, 72^{\circ} \mathrm{C} 30 \mathrm{~s}$, and a final cycle at $72^{\circ} \mathrm{C}$ during 10

131 min. Purification and sequencing were made as explained above.

\section{Analyses of sequences}

133 The sequences obtained were edited using BioEdit program ${ }^{20}$ and compared with

134 GenBank database (www.ncbi.nlm.nih.gov/genbank/) using BLAST Nucleotide tool

135 (nBLAST). Species assignment was done to the best match reference sequence within

136 GenBank. Species assignation was confirmed from phylogenetic methodology. A

137 Neighbor-Joining tree containing the problem sequences and reference sequences from

138 GenBank was reconstructed with MEGA version $6,{ }^{21}$ with Tamura Nei model ${ }^{22}$ and

139 uniform substitution rates. Robustness of the Neighbor-Joining topology was assessed

140 using 10,000 bootstrap replicates.

\section{RESULTS}

142 DNA yields obtained from the analyzed candies ranged between undetectable

$143<0.0005 \mathrm{ng} / \mu 1$ in seven products (samples \#3, \#7, \#8, \#10, \#15, \#17 and \#18) to

$1440.328 \mathrm{ng} / \mu \mathrm{l}$ in the Portuguese gelatin of sample\#6 (Table 1). Positive PCR amplification

145 of one or the two assayed markers occurred from all except one product, fish gummies 
146 (sample\#3, Table 1). This means that DNA was present at least in 17 out of 18 samples

147 (94.4\%), although in very low (undetectable) quantity in six of them.

148 In the cases of successful DNA amplification, clean negative controls were obtained in

149 all PCR (e.g., Fig. 2). The number of sequences retrieved in total from the 17 candies

150 with positive PCR amplification was 118 for the $16 \mathrm{~S}$ rDNA gene and 94 for the rbcL

151 gene. The sequences were submitted to the European Nucleotide Archive (ENA), from

152 the European Bioinformatics Institute in the European Molecular Biology Laboratory,

153 EMBL-EBI (www.ebi.ac.uk/). Their accession numbers are HG964177-HG964248. For

154 the 16S rRNA gene, amplicons ranged 116-122 bp in length and exhibited nucleotide

155 polymorphisms corresponding to 13 haplotypes that allowed to unambiguously

156 identifying five animal species to species level: cow Bos taurus, pig Sus scrofa, chicken

157 Gallus gallus, deep Cape hake Merluccius paradoxus, human Homo sapiens. One

158 haplotype could be assigned only at genus level (hake Merluccius sp.). For the rbcL

159 gene, 159 bp long amplicons were obtained representing 14 haplotypes. Seven species

160 were unambiguously identified from the haplotypes found for this DNA region: maize

161 Zea mays, soya Glicine max, cacao Theobroma cacao, onion Allium cepa, tobacco

162 Nicotiana tabacum and chestnut Castanea sativa. One haplotype exhibited the same E-

163 value for two match hits with references sequences of wheat (Triticum sp.) and rye

164 (Secale cereale), of the family Poaceae, and another with cumin (Cuminum cyminum)

165 and carrot (Daucus carota), of the family Apiaceae. The remaining haplotypes could

166 taxonomically assign the sequences only at genus (beans, Vicia sp.; rice, Oryza sp.;

167 honeybush, Ciclopia sp.) or family level (Oleaceae). In spite of the short length of the

168 two sequences here employed, the reconstructed Neighbor-Joining trees exhibited a

169 rather good phylogenetic signal, grouping together the haplotypes of the same species or

170 genus in the tree reconstructed from 16S rDNA sequences (Fig. 3). Likewise, the tree 
171 reconstructed from rbcL sequences clustered haplotypes by family (Fig. 4); however,

172 and as expected from their shorter length, bootstrapping values were lower than in the

173 16S rDNA-based tree, and some phylogenetic discrepancies occurred; for example, the

174 sequences identified as $A$. cepa (onion), expected to be clustered with other Liliopsida

175 such as the cereals, were alone in a branch apart.

176 Regarding candies composition, from 16S rDNA one animal species was found for most

177 samples (Table 2), pig (S. scrofa) being the most frequent (in $64.7 \%$ of candies)

178 followed by cow (B. taurus) (47.1\% of candies), hake (genus Merluccius) (11.8\%) and

179 chicken (G. gallus) (5.5\%). From rbcL sequences (Table 2) a mixture of at least three

180 plant species was detected in eight of the samples analyzed (44.4\%). Seven samples

181 contained maize (Z. mays) and also seven samples contained beans or related species

182 (Vicia sp.). Less frequent ingredients were cereals of the tribe of wheat/rye; soya, rice,

183 honeybush and chestnut; tobacco, cacao, cumin and Oleaceae (found from five; two;

184 and one samples respectively). Some ingredients were unexpected, since contamination

185 from the analysis process can be discarded given clean negative PCR controls and strict

186 measures of sterility, such as human DNA and tobacco found in eight (44\% samples:

$187 \# 2, \# 7, \# 8, \# 11, \# 13, \# 14, \# 15$ and $\# 17)$ and one (\#13) candies respectively (Table 2).

188 Many species detected from DNA were not stated in the labels and vice versa (Table 2).

189 Only one of the samples analyzed provided DNA results concordant with the label: the

190 gelatin powder of Sample\#1 (Tables 1 and 2) that declared to contain porcine gelatin

191 and contained porcine DNA. Other DNA-label concordances occurred in a few samples:

192 \#11 label also declared porcine gelatin and porcine DNA was found; \#2 and \#7 declared

193 corn and contained corn DNA, as did occur in \#8 for soya and \#15 for wheat. In general

194 there was a difference between the means of animal and plant species found only from

195 DNA and only from labels (Fig. 5, Table 2). More animal species were found from 
196 DNA than from labels with Horreo et al. ${ }^{18}$ primers, whereas for plants it was the

197 opposite, with more plants and fruits stated in the labels than found from DNA with

198 Han et al. ${ }^{19}$ primers.

199 Some cases found in this study can be problematic for consumers. Pig, not accepted by

200 some religions, is one example. Pig traces appeared but were not declared in $55.6 \%$ of

201 samples (Fig. 4). Moreover, two samples labeled as apt for vegetarians (vanilla custard,

202 Sample\#2; agar, Sample\#5) contained pig traces. Another possible problematic case

203 was the failure to declare fish content, although hake traces were present in three

204 samples.

205

\section{DISCUSSION}

206

207

208

209

210

211

212

213

214

215

216

217

218

219

Our results revealed that DNA traces were present in most analyzed commercial candies, and that its quality and concentration was sufficient for successful PCR amplification of short DNA sequences of species-specific value. The results obtained here confirm the power of DNA tests for detecting traces of ingredients in complex food matrices, supporting other authors who used DNA for identifying unwanted species in candy, for instance Demirhan et al. ${ }^{7}$ Most studies use specific markers for identifying only targeted species or DNA sequences; for example the mentioned study targeting porcine, ${ }^{7}$ markers for detecting genetically modified maize and soy, ${ }^{12}$ or saffron in highly processed products. ${ }^{15}$ Here we have followed a different approach of PCRcloning of conserved DNA sequences using universal primers, instead of speciestargeted ones, because our objective was to detect as many species as possible. Indeed, not finding a species in only a dozen sequences (from cloning) cannot ensure that such species is absent from the product; it could be present in low proportion and remain undetected. Due to the many ingredients contained in candy, this process could be 
220 considerably improved using next generation sequencing technology (NGST): high-

221 throughput sequencing approaches after direct DNA extraction from a matrix or

222 environmental sample. Capable to generate millions of sequences at the same time,

223 NGST is now used in ecology for biodiversity monitoring, and its application in food

224 sciences has been suggested for microbes in complex food matrices. ${ }^{23,24}$

225 It should to be taken into account that the absence of DNA traces of a species in a

226 product does not imply that species is really absent; DNA can be so degraded that PCR

227 may fail, and/or primers may fail to anneal if they are insufficiently specific for a

228 taxonomic group. Conversely, if DNA traces of a species occur in a product and

229 contamination can be reasonably discarded, as it is the present case, there is no doubt

230 that the species is really present in that product. Despite quite limited sample size, in our

231 results we found a surprising and unexpected high level of failure to declare species

232 contents in commercial packed candies. Many undeclared species were detected in more

233 than $90 \%$ of the analyzed candies, and some of them could raise ethical issues (pig;

234 animal species in vegetarian candies) for many consumers. Since the candy trade is

235 widely globalized, ${ }^{25}$ and our study was done from candies made in five different

236 countries, the results here obtained could likely be generalized.

237 Regulations of candy labelling are not homogeneous worldwide and each country has

238 specific laws, generally focused on allergenic ingredients. For example, in the US it is

239 mandatory to list major allergens contained in the ingredients on the label of packed

240 food, including candy, stating the species the major allergen is derived from (Food

241 Allergen Labelling and Consumer Protection Act of 2004; Public Law 108-282, Title

242 II). In European common law, packed food must also display a list of potential allergens

243 separated from the list of ingredients (EU 1169/2011). In addition to this general

244 normative, at national level some regulations are specifically applied to candy; for 
245 example, in Spain the Royal Decree 1245/2008 states that packed candies must exhibit

246 information about allergens on the label. The results of the present study suggest that

247 the current labeling normative should be improved. At least the species used for the

248 gelatin should be disclosed. The consumer should be informed about fish, which can

249 trigger allergic reactions if inadvertently eaten with candy. ${ }^{11}$ On the other hand, pig and

250 cow are frequently employed to produce commercial gelatin, ${ }^{6,7}$ thus their presence in

251 most candies here analyzed is not surprising. However, their occurrence in candies

252 labelled "For vegetarians" could be considered a fraud and undermine the choice rights

253 of vegetarian consumers.

254 The causes of failure for declaring all the species detected in this study are probably

255 diverse. Some ingredients could have been merely listed as "colorants" or "spice",

256 without disclosing the species contained. ${ }^{26}$ In some cases it could be likely deliberate,

257 as in Sample\#5 supposedly made only from algae (colorants were not stated) but

258 containing really pig, bean and honeybush traces. However in other cases the presence

259 of some traces could be inadvertent. Some ingredients could have been accidentally

260 acquired during the process of packing. ${ }^{27}$ This could happen also in the cases of

261 contamination with human DNA and even tobacco; it is very difficult to imagine that

262 negligent manipulation of food products is deliberate. However, although likely not

263 deliberate in some (perhaps in many) cases, the results found our study strongly support

264 the need of a more careful control of the international candy market.

\section{CONCLUSIONS}

266 Using DNA analysis we have detected a generalized failure to inform about ingredients

267 in commercial candies from five producer countries. DNA traces of many species

268 undeclared in the labels like porcine, fish, soya, honeybush and others were found from 
269 most analyzed samples. Undeclared porcine DNA was found in samples labeled as "For

270 vegetarians", undermining the rights of vegetarian consumers. A more strict control of

271 commercial candies is recommended, applying methodology based on DNA-tests or

272 Next Generation Sequencing Technology, which could obtain higher resolution on the 273 composition of these sweets.

\section{ACKNOWLEDGEMENTS}

275 This research was financially supported by Fundacion Mapfre (SV13-MAPFRE-1), 276 Regional Government of the Principado de Asturias, Spain (Research Grant 277 GRUPIN14-093) and Campus of Excellence of the University of Oviedo. M.M-C. holds 278 a Spanish National Grant (reference AP-2010-5211). The data reported in this paper are 279 archived at the following databases: European Nucleotide Archive (ENA), from the 280 European Bioinformatics Institute in the European Molecular Biology Laboratory, 281 EMBL-EBI (http://www.ebi.ac.uk/). We also acknowledge the assistance of Daniel 282 Serna Fuente (Sequencing Unit of the University of Oviedo).

\section{REFERENCES}

1. Popkin BM and Nielsen, The Sweetening of the World's Diet. Obesity 11: 13251332 (2003). 
4. Jansen E, Mulkens S and Jansen A, Do not eat the red food!: Prohibition of snacks leads to their relatively higher consumption in children. Appetite 49: 572577 (2007).

5. Madsen C, Chemicals in food and allergy: fact and fiction. Environ. Toxicol. Pharmacol. 4: 115-120 (1997).

6. Daeyeon K and Sea CM, Trout skin gelatin-based edible film development. $J$. Food Sci. 77: E240-E246 (2012).

7. Demirhan Y, Ulca P and Senyuva HZ, Detection of porcine DNA in gelatine and gelatine-containing processed food products-Halal/Kosher authentication. Meat Sci. 90: 686-689 (2012).

8. Simon RA, Adverse reactions to food and drug additives. Immunol. Allerg. Clin. North Am. 16: 137 (1996).

9. Ramesh S, Food Allergy Overview in Children. Clin. Rev. Allergy Immunol. 34: 217-230 (2008).

10. Al- Ahmed N, Alsowaidi S and Vadas P, Peanut Allergy: An Overview. Allergy Asthma Clin. Immunol. 4: 139-143 (2008).

11. Kuehn A, Hilger C and Hentges F, Anaphylaxis provoked by ingestion of marshmallows containing fish gelatin. J. Allergy Clin. Immunol. 123: 708-709 (2009).

12. Arun OO, Yilmaz F and Muratoglu K, PCR detection of genetically modified maize and soy in mildly and highly processed foods. Food Control 32: 525-531 (2013). 
313

314

315

316

317

318

319

320

321

322

323

324

325

326

327

328

329

330

331

332

333

334
13. Bornatowski H, Braga RR, Simoes V and Jean R, Shark Mislabeling Threatens Biodiversity. Science 340: 923-923 (2013).

14. Marko PB, Lee SC, Rice AM, Gramling JM, Fitzhenry TM, McAlister JS, Harper GR and Moran AL, Mislabelling of a depleted reef fish. Nature 430: 309-310 (2004).

15. Torelli A, Marieschi M and Bruni R, Authentication of saffron (Cronus sativus L.) in different processed, retail products by means of SCAR markers. Nature 36: 126-131 (2014).

16. Poms RE, Klein CL and Anklam E, Methods for allergen analysis in food: a review. Food Addit. Contam. 21: 1-31 (2004).

17. Mackie IM, Pryde SE, Gonzales-Sotelo C, Medina I, Pérez-Martín R, Quinteiro J, Rey-Mendez M and Rehbein H, Challenges in the identification of species of canned fish. Trends Food Sci. Technol. 10: 9-14 (1999).

18. Horreo JL, Ardura A, Pola IG, Martinez JL and García-Vázquez E, Universal primers for species authentication of animal foodstuff in a single polymerase chain reaction. J. Sci. Food Agric. 93: 654-361 (2013).

19. Han JX, Wu YJ, Huang WS, Wang B, Sun CF, Ge YQ and Chen Y, PCR and DHPLC methods used to detect juice ingredient from 7 fruits. Food control 25 : 696-703 (2012).

20. Hall TA, BioEdit: a user-friendly biological sequence alignment editor and analysis program for Windows 95/98/NT. Nucleic Acids Symp. Ser. 41: 95-98 (1999). 
21. Tamura K, Stecher G, Peterson D, Filipski A and Kumar S, MEGA6: Molecular Evolutionary Genetics Analysis Version 6.0. Mol. Biol. Evol. 30: 2725-2729 (2013).

22. Tamura $\mathrm{K}$ and Nei M, Estimation of the number of nucleotide substitutions in the control region of mitochondrial DNA in humans and chimpanzees. Mol. Biol. Evol. 10: 512-526 (1993).

23. Gui J and Patel IR, Recent Advances in Molecular Technologies and Their Application in Pathogen Detection in Foods with Particular Reference to Yersinia. J. Pathog. 2011: 1-11 (2011).

24. Ercolini D, High-Throughput Sequencing and Metagenomics: Moving Forward in the Culture-Independent Analysis of Food Microbial Ecology. Appl. Environ. Microbiol. 79: 3148-3155 (2013).

25. Krummel DA, Seligson FH, Guthrie HA and Gans DA, Hyperactivity: Is candy causal? Crit. Rev. Food Sci. Nutr. 36: 31-47 (2009).

26. Pieretti MM, Chung D, Pacenza R, Slotkin T and Sicherer SH, Audit of manufactures products: Use of allergen advisory labels and identification of labeling ambiguities. J. Allergy Clin. Immunol. 124: 337-341 (2009).

27. Laemmel S and Schnadt S, Food labelling as seen by the allergenic consumer. Results of the inquiry concerning current food marking regarding allergenic ingredients. Allergologie, 31: 33-40 (2009). 


\section{TABLES}

Table 1: summary of candy samples analyzed.

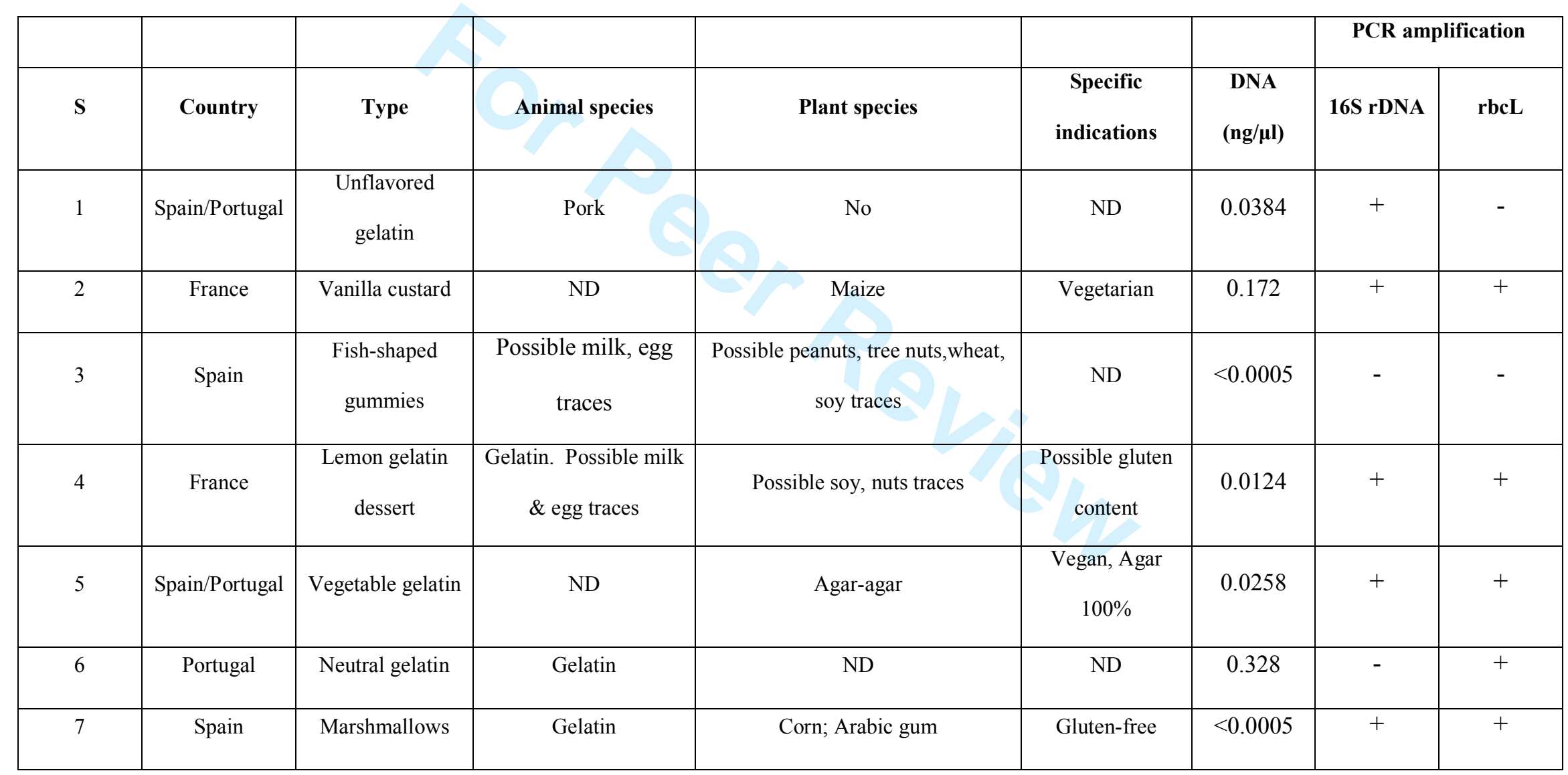




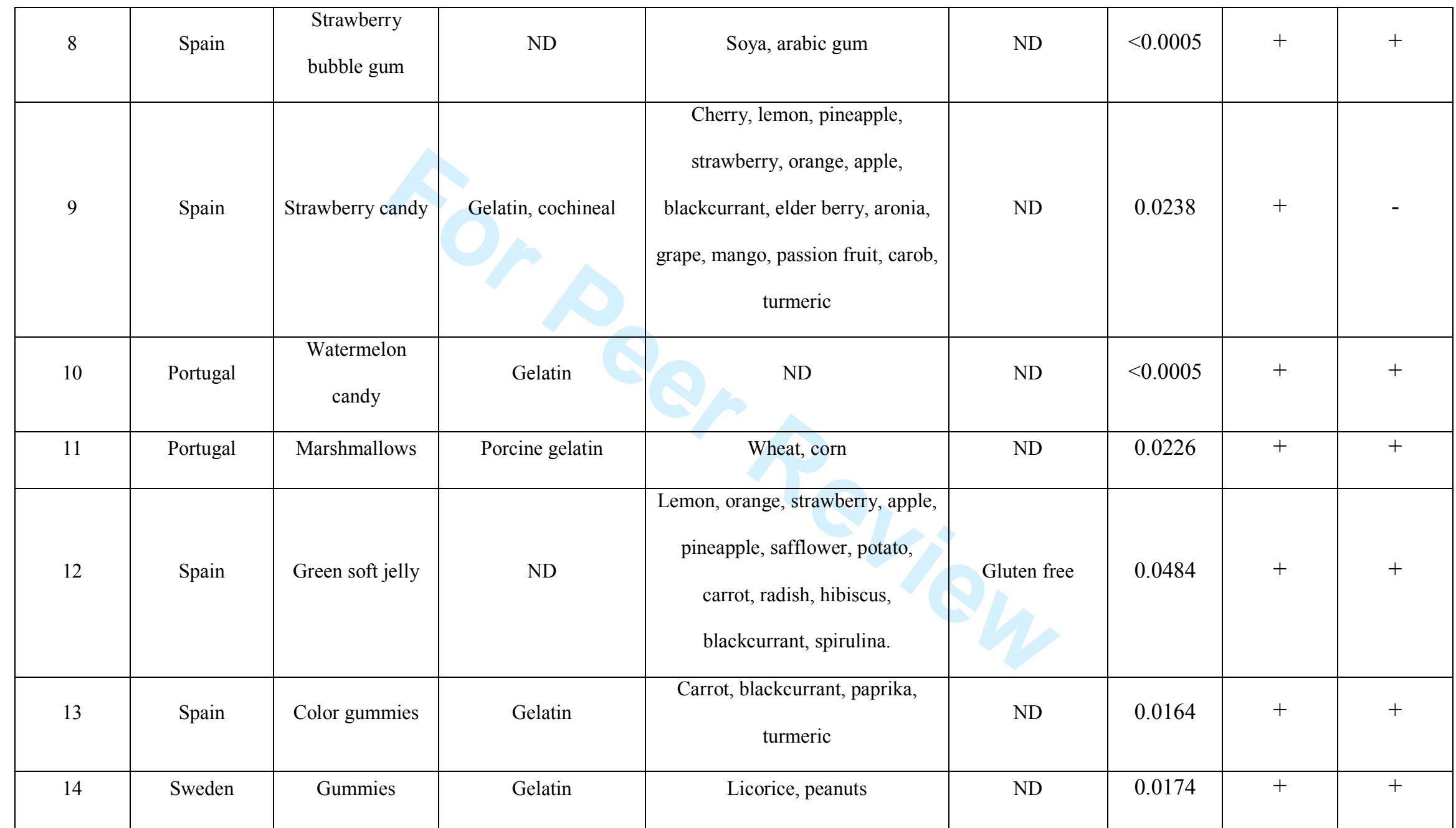




\begin{tabular}{|c|c|c|c|c|c|c|c|c|}
\hline 15 & Portugal & $\begin{array}{c}\text { Pineapple gelatin } \\
\text { dessert }\end{array}$ & $\begin{array}{l}\text { Gelatin; Possible eggs } \\
\qquad \& \text { milk traces }\end{array}$ & Possible wheat traces & ND & $<0.0005$ & + & + \\
\hline 16 & Spain & Strawberry candy & Gelatin, cochineal & $\begin{array}{l}\text { Cherry, lemon, pineapple, } \\
\text { strawberry, orange, apple, } \\
\text { blackcurrant, elder berry, aronia, } \\
\text { grape, mango, passion fruit, carob, } \\
\text { turmeric }\end{array}$ & ND & 0.0208 & + & + \\
\hline 17 & Spain & Sherbet powder & ND & $\mathrm{ND}$ & Sugar \& flavours & $<0.0005$ & + & - \\
\hline 18 & Turkey/Spain & Fruit bubble gum & Gelatin & $\begin{array}{l}\text { Watermelon, pineapple, melon, } \\
\text { arabic gum, turmeric }\end{array}$ & $\begin{array}{c}\text { Contains } \\
\text { Brilliant Blue } \\
\text { FCF }\end{array}$ & $<0.0005$ & + & + \\
\hline
\end{tabular}

Country of origin, type of product, animal and plant species declared in the label, specific indications for consumers, DNA quantity determined by fluorometry, PCR amplification of the markers assayed (positive or negative as visualized in agarose gel). 
Table 2: Composition of the analyzed candy samples as identified from DNA.

\begin{tabular}{|c|c|c|c|c|c|c|c|c|c|c|c|c|c|c|c|c|c|c|c|}
\hline & $N^{o} s p$ & ecies & & & & & & & & & & & & & & & & & \\
\hline Sample & Animals & Plants & Clones & Cow & Pork & Hake & Chicken & Beans & Rice & Cereals & Apiaceae & Oleaceae & Onion & Chestnut & Honeybush & Soya & Cacao & Corn & Contaminants \\
\hline 1 & $1(1)$ & $0(0)$ & 8 & - & + & - & - & - & - & - & - & - & - & - & - & - & - & - & - \\
\hline 2 (veg) & $1(0)$ & $2(1)$ & 11 & - & + & - & - & - & - & + & - & - & - & - & - & - & - & + & + \\
\hline 3 & $0(2)$ & $0(4)$ & 0 & - & - & - & - & - & - & - & - & - & - & - & - & - & - & - & - \\
\hline 4 & $2(3)$ & $4(2)$ & 14 & + & + & - & - & + & - & + & - & - & + & - & - & - & + & - & - \\
\hline 5 (veg) & $1(0)$ & $2(1)$ & 12 & - & + & - & - & + & - & - & - & - & - & - & + & - & - & - & - \\
\hline 6 & $0(1)$ & $3(0)$ & 6 & - & - & - & - & + & + & - & + & - & - & - & - & - & - & - & - \\
\hline 7 & $4(1)$ & $1(2)$ & 16 & + & + & + & + & - & - & - & - & - & - & - & - & - & - & + & + \\
\hline 8 & $3(0)$ & $2(2)$ & 10 & + & + & + & - & + & - & - & - & - & - & - & - & + & - & - & + \\
\hline 9 & $1(2)$ & $0(14)$ & 5 & + & - & - & - & - & - & - & - & - & - & - & - & - & - & - & - \\
\hline
\end{tabular}




\begin{tabular}{|l|c|c|c|c|c|c|c|c|c|c|c|c|c|c|c|c|c|c|c|}
\hline 10 & $1(1)$ & $3(0)$ & 13 & + & - & - & - & + & - & + & - & - & - & - & - & - & - & + & - \\
\hline 11 & $1(1)$ & $0(2)$ & 8 & - & + & - & - & - & - & - & - & - & - & - & - & - & - & - & + \\
\hline 12 & $1(0)$ & $3(12)$ & 17 & + & - & - & - & + & - & - & - & + & - & - & + & - & - & - & - \\
\hline 13 & $2(1)$ & $2(4)$ & 14 & + & + & - & - & + & - & - & - & - & - & - & - & - & - & + & + \\
\hline 14 & $2(1)$ & $3(2)$ & 15 & + & + & - & - & - & - & + & - & - & - & - & - & + & - & + & + \\
\hline 15 & $2(3)$ & $2(1)$ & 17 & - & + & + & - & - & + & + & - & - & - & - & - & - & - & - & + \\
\hline 16 & $1(2)$ & $3(14)$ & 19 & + & - & - & - & - & - & + & - & - & - & + & - & - & - & + & - \\
\hline 17 & $1(0)$ & $0(0)$ & 4 & - & + & - & - & - & - & - & - & - & - & - & - & - & - & - & + \\
\hline 18 & $1(1)$ & $3(5)$ & 23 & - & + & - & - & - & - & - & - & - & - & + & + & - & - \\
\hline
\end{tabular}

Number of animal and plant species from DNA (declared in the label in parenthesis); number of clone sequences obtained from each sample; presence/absence of different ingredients authenticated from DNA sequences as +/-. Samples indicated for vegetarians are marked with (veg) 
2 Figure 1: Photographs of different samples of this study: (1) Sample\#1, gelatin powder

3 (2) Sample\#3, fish gummy; (3) Sample\#2, pre-cooked mix for vanilla custard (4);

4 Sample\#4, lemon jelly; (5) Sample\#8, strawberry gum; (6) Sample\#7, marshmallow; (7)

5 Sample\#9, strawberry candy; (8) Sample\#10, watermelon jelly; (9) Sample\#12, green

6 candy; (10) Sample\#18, fruit gum; (11) Sample\#11, marshmallow; (12) Sample\#14,

7 candy; (13) Sample\#13, soft candy.

8 Figure 2: Photography of 2\% agarose gel stained with ethidium bromide and visualized 9 under UV light showing PCR products obtained with the 16S-H (A) and Rbc-L (B)

10 primers; from left to right in A gel: positive control, samples 8-11 (two lanes/sample),

11 negative control, empty lane, DNA ladder (marker of size, in base pairs); B gel: samples

12 8-11 (two lanes/sample), positive control, DNA ladder and negative control.

13 Figure 3: Neighbor-Joining tree reconstructed from the 16S rDNA sequences obtained 14 from the analyzed candy. The haplotype name is followed by the closest taxonomic 15 match. Reference sequences are included indicated as ref_with their GenBank 16 accession number. A sequence of the limpet Patella depressa was employed as 17 outgroup.

18 Figure 4. Neighbor-Joining tree reconstructed from the rbcL sequences obtained from 19 the analyzed candy. The haplotype name is followed by the closest taxonomic match. 20 Reference sequences are included indicated as ref_with their GenBank accession 21 number. A sequence of the green alga Fucus vesiculosus was employed as outgroup.

22 Figure 5: Mean number per candy sample of animal and plant species of the following 23 types: concordant, declared only in the labels and found only from DNA. 


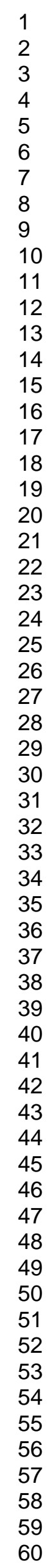

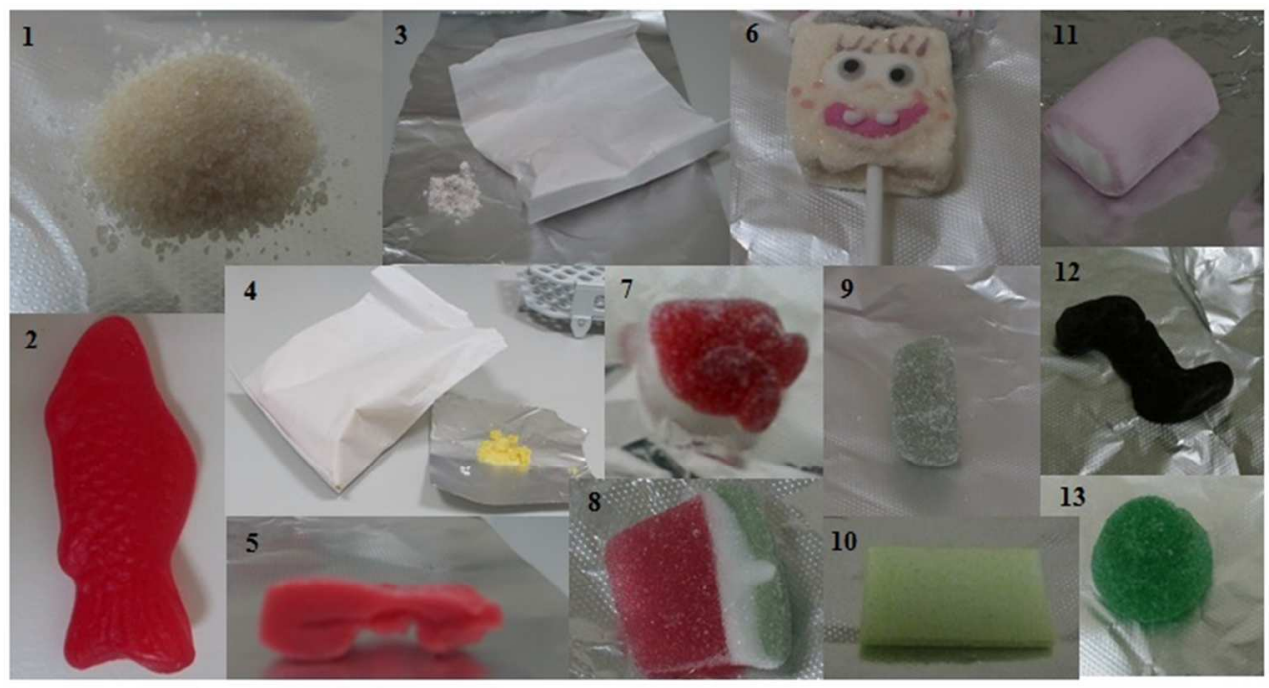

$202 \times 111 \mathrm{~mm}(96 \times 96 \mathrm{DPI})$ 

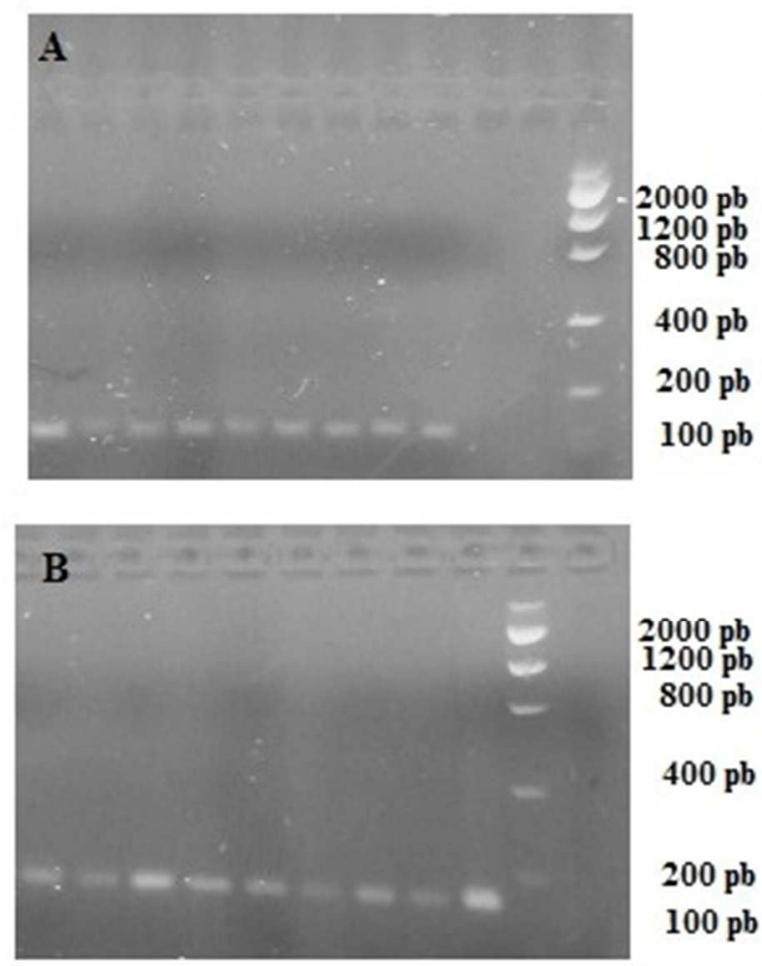

$81 \times 107 \mathrm{~mm}(96 \times 96$ DPI) 
1

2

3

4

5

6

7

8

9

10

11

12

14

15

16

17

18

19

20

21

22

23

24

25

26

27

28

29

30

31

32

33

34

35

36

37

38

39

40

41

42

43

44

45

46

47

48

49

50

51

52

53

54

55

56

57

58

59

60

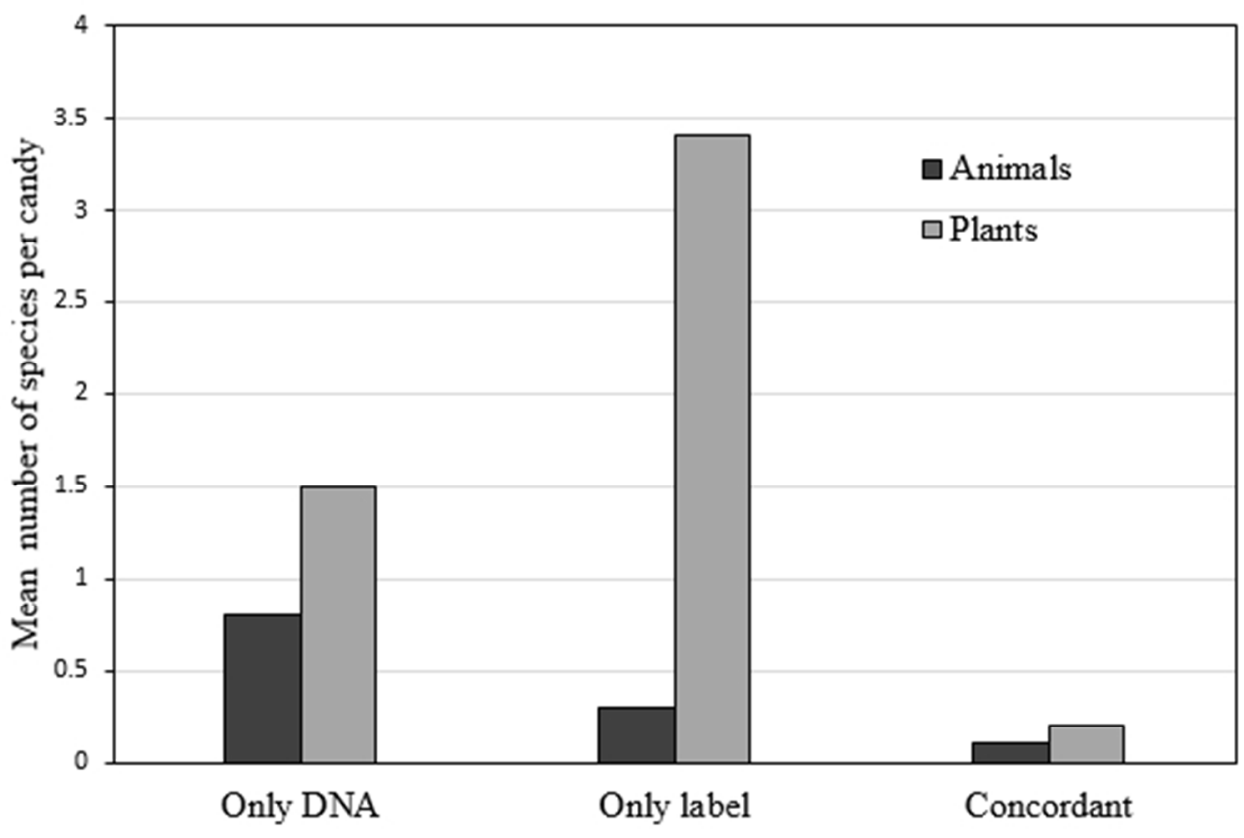

$152 \times 99 \mathrm{~mm}(96 \times 96 \mathrm{DPI})$ 